\title{
Agriculture and Aggregate Productivity: A Quantitative Cross-Country Analysis ${ }^{\dagger}$
}

\author{
Diego Restuccia \\ University of Toronto \\ Dennis Tao Yang \\ Virginia Polytechnic Institute and State University \\ Xiaodong Zhu \\ University of Toronto
}

August 2003

\begin{abstract}
${ }^{\dagger}$ We would like to thank Loren Brandt, V.V. Chari, Andrés Erosa, Mukesh Eswaran, George Norton, and Aloysius Siow for helpful discussions and comments. We have also benefited from the comments of seminar participants at the University of Toronto, Western Ontario, ITAM, and the CIRPEE Development Economics mini-conference in Quebec City. An earlier version of this paper was presented at the 2001 Society for Economic Dynamics Meeting in Stockholm and the 2001 Canadian Macroeconomic Study Group Meeting in Vancouver. All remaining errors are our own. Contact information: Department of Economics, University of Toronto, 150 St. George Street, Toronto, Ontario, M5S 3G7, Canada. E-mail: diego.restuccia@utoronto.ca, deyang@vt.edu,xzhu@chass.utoronto.ca.
\end{abstract}




\begin{abstract}
A decomposition of aggregate labor productivity based on internationally comparable data from FAO and Penn World Tables reveals that high labor shares and low productivity in agriculture are mainly responsible for poor countries' current position in the world income distribution. Using a two-sector general equilibrium model, we argue that differences in total factor productivity (TFP) and barriers to using modern intermediate inputs in agricultural production can largely account for the observed cross-country differences in both the labor share and productivity in agriculture. Furthermore, our model with agriculture can account for $89 \%$ of the observed aggregate labor productivity differences across countries, performing much better than a one-sector growth model with the same exogenous differences in TFP.

Keywords: Agriculture, Land, Subsistence, Intermediate Input, Barriers, Productivity, International Comparisons.

JEL Classification: O4, O1.
\end{abstract}




\section{Introduction}

This paper examines the role of agriculture in accounting for international differences in output per worker. To see why agriculture is important, consider the following facts. In 1985, GDP per worker in the richest 5 countries is 32 times that of the poorest 5 countries. This is an enormous difference in aggregate labor productivity. However, for the same two groups of countries, the productivity difference in agriculture is even larger: agricultural GDP per worker in the richest countries is 71 times that of the poorest countries! In contrast, the difference in nonagricultural GDP per worker is less than a factor of 4. Despite their very low agricultural productivity, the poorest countries allocate $90 \%$ of their labor force to agriculture, compared to only $5 \%$ in the richest countries. (For a more comprehensive documentation of these observations see Figure 1 and Table 6 in the Appendix.) ${ }^{1}$ These facts provoke two important questions: Why are so many people in poor countries still working in agriculture despite the sector's extremely low productivity? And why is agricultural labor productivity so low in poor countries? Clearly, satisfactory answers to both of these questions are essential to understanding aggregate income differences across countries. ${ }^{2}$

\footnotetext{
${ }^{1}$ The data for aggregate GDP are from the Penn World Tables and the data for agriculture are from the Food and Agricultural Organization of the United Nations (FAO). See the Appendix and footnote 7 for detailed descriptions.

${ }^{2}$ To illustrate the importance of labor shares and sectoral productivity in accounting for aggregate output per worker differences across countries, consider the following decomposition of aggregate output per worker:

$$
\frac{Y}{N}=\frac{Y_{n}}{L_{n}}\left(1-\frac{L_{a}}{N}\right)+p^{*} \frac{Y_{a}}{L_{a}} \frac{L_{a}}{N},
$$

where $Y_{i} / L_{i}$ is output per worker and $L_{i} / N$ is labor share in sector $i, a$ denotes agriculture and $n$ nonagriculture, and $p^{*}$ is the relative price of agriculture. Using the information for the 5 richest and poorest countries contained in Appendix E and assuming $p^{*}=1$, consider a hypothetical country that initially observes the same labor shares and sectoral productivities of the richest countries. From this initial situation assume instead that this country observes the labor shares of the poorest countries. Then relative aggregate productivity between the richest countries and this hypothetical country would be a factor of 2 to 1 , which is
} 
The objective of this paper is to provide quantitative answers to the questions posed above within a general equilibrium framework. At a qualitative level, there is a fairly straightforward answer to the first question: Poor countries have a large portion of their labor force working in agriculture because they have what T.W. Schultz (1953) called the food problem - due to low labor productivity, these countries have to allocate a large share of labor to farming in order to meet subsistence food requirements. ${ }^{3}$ The central question is, then, why are poor countries so unproductive in agriculture? Using a relatively standard two-sector general equilibrium model with subsistence food requirements, we show in this paper that low agricultural labor productivity in poor countries can largely be accounted for by two factors: (1) low levels of total factor productivity (TFP) and (2) barriers to using modern intermediate inputs in agricultural production. The model implies that these two factors can quantitatively account for the large labor share in agriculture observed in poor countries. Furthermore, in our model we find that differences in these two factors can also account for $89 \%$ of the observed aggregate labor productivity differences across countries. Our analysis suggests that to raise agricultural and aggregate productivity in poor countries, it is important to remove the constraints to using efficient technologies and the barriers that prevent farmers from using modern intermediate inputs more extensively.

only $1 / 16$ of the actual difference between the richest and poorest countries. Again starting from the initial situation, assume instead that this country observes the sectoral productivities of the poorest countries. Then aggregate productivity would be a factor of 4 to 1 , which is $1 / 8$ of the actual difference between the richest and poorest countries. From this accounting perspective, both factors together - labor shares and sectoral productivity - are essential in understanding international differences in aggregate productivity.

${ }^{3}$ For empirical evidence supporting subsistence food requirements, see Rosenzweig and Wolpin (1993) and Atkeson and Ogaki (1996, 1997). Gollin, Parente and Rogerson (2001) provide a numerical illustration showing that low labor productivity combined with subsistence food requirements can generate a large share of labor in agriculture. Note that this relationship between productivity and labor share does not have to hold if a country can import food. However, as Gollin, Parente and Rogerson (2001) point out, the evidence is that developing countries only import limited quantity of basic foodstuffs. 
Many economists emphasize the importance of TFP in accounting for international differences in aggregate labor productivity (e.g., Klenow and Rodriguez-Clare, 1997; Hall and Jones, 1999; Prescott, 1998; Parente and Prescott, 2000; and Hsieh and Klenow, 2002). We argue here that differences in TFP across countries are also important in accounting for differences in agricultural labor productivity. When a country has low TFP, it translates directly into low agricultural productivity. In addition, there is an indirect effect. Because of subsistence food requirements and land being a fixed factor in farming, a low TFP level implies that more labor has to be allocated to agriculture, which results in a lower land-tolabor ratio and a further reduction in agricultural labor productivity. This indirect effect explains in part why labor productivity in agriculture relative to that in nonagriculture is much lower in poor countries.

There is an extensive literature in economic development that addresses the issue of low agricultural productivity in poor countries. In that literature, it is emphasized that the major constraints to improving agricultural productivity in poor countries are policies and institutions that prevent the use of science-based modern farming technologies (e.g., Schultz, 1964; Hayami and Ruttan, 1970 and 1985; and Huffman and Evenson, 1993.) In particular, because modern agricultural technologies are often embodied in some intermediate inputs such as chemical fertilizers, new seeds, pesticides, many development economists have emphasized factor market distortions that reduce farmers' incentive in using these inputs as constraints to raising agricultural productivity in developing countries (e.g., Hayami and Ruttan, 1985; and Timmer, 1988). Cross-country data corroborate with this established view in the development literature. Using common international prices, Figure 2 documents 
the ratio of intermediate input expenditures to final output in agricultural production, ${ }^{4}$ revealing a systematic positive relationship between the extent of intermediate input use and agricultural labor productivity (the correlation coefficient is 0.62). While intermediate inputs account for $40 \%$ of final agricultural output in the 5 richest countries, they only account for $10 \%$ of final output in the 5 poorest countries. ${ }^{5}$

Factor market distortions that affect agriculture are pervasive in developing countries due to government policies that systematically discriminate against agriculture (see Krueger, Schiff and Valdes, 1991). We examine two types of factor market distortions in accounting for international differences in intermediate input use. First, we consider direct barriers as reflected in the cost of these inputs. For example, protection of domestic industries (e.g. fertilizer production) that often occur in poor developing countries force farmers to pay more for intermediate inputs than they would have to pay for the same inputs at world prices. Protection also makes domestic producers less efficient, which raises the prices of their products. In addition, government policies in poor countries often promote under-investment in necessary infrastructures such as road and distribution systems, making it difficult to deliver intermediate inputs to dispersed farm households and effectively increasing farmers' cost of using these inputs. Second, we analyze the impact of indirect barriers associated with labor market segmentation. Policies such as restrictions on rural to urban migration and institutional protection of industrial wages tend to reduce labor mobility between the

\footnotetext{
${ }^{4}$ Here, and throughout the paper, intermediate inputs refer to inputs that are produced outside the agricultural sector (e.g., chemical fertilizers, pesticides, processed seeds, fuel, and energy). So, they do not include feeds and seeds that are from within the agricultural sector.

${ }^{5}$ Interestingly, the ratio of expenditures on intermediate inputs to output across poor and rich countries compare in magnitude to the ratio of real physical capital investment to output observed across poor and rich countries. (See Restuccia and Urrutia, 2001).
} 
agricultural and nonagricultural sectors and suppress wages in agriculture relative to those in nonagriculture (see Rosenzweig, 1988). By reducing the labor cost in agriculture, these policies encourage farmers to substitute labor for other inputs and therefore are indirect barriers to intermediate input use. ${ }^{6}$

In our quantitative exercise, we use aggregate data from the Penn World Tables and data for agriculture from the Food and Agricultural Organization (FAO) of the United Nations. To our knowledge, the FAO data are the best available for studying agricultural productivity across countries. ${ }^{7}$ We calibrate cross-country TFP differences by using GDP per-worker differences in the nonagricultural sector. We measure direct barriers to intermediate input use by the relative price of intermediate input to nonagricultural output, and distortions in the labor market by the average wage differential between the agricultural and nonagricultural sectors. Taking these measures as exogenous, the model generates implications for intermediate input to output ratios, labor shares and productivity in agriculture, as well as aggregate output per worker for all countries in the sample. The quantities for each of these variables implied by the model match well with actual observations in the data. In particular, our model implies a ratio of 34 to 1 in agricultural labor productivity between

\footnotetext{
${ }^{6}$ See Manuelli and Seshadri (2003) for evidence that low labor costs were responsible for the initially slow adoption of one particularly type of modern inputs - tractors - in U.S. agriculture.

${ }^{7}$ These data are relevant for our purpose because the methodology of aggregating agricultural goods follows a procedure similar to the methodology used in the Penn World Tables for the comparison of aggregate output across countries. The idea is to price a representative and common basket of goods across countries and convert output valued at domestic prices into a measure of output valued at a common set of prices (international prices), rendering comparable measures of output that are less subject to price distortions across countries. Moreover, the data are relevant for international comparisons of agricultural output because it uses producer agricultural prices, that is, prices received by farmers at the farm gate that exclude charges related to transportation, distribution, and marketing of products to the consumers. These activities belong to the service sector and should not affect agricultural measures of output. This is particularly relevant as service prices vary systematically with development. (See Summers and Heston, 1991).
} 
the richest and poorest countries, which accounts for about half of the observed disparity (71 to 1). Regarding aggregate productivity, our model implies a factor of 22 in output per worker differences between the richest and poorest countries, while the observed difference is 32. Compared to a one-sector model with the same exogenous TFP differences, our model with agriculture generates 5 times more output per worker differences between the richest and poorest countries.

Our paper is closely related to the literature that uses variants of the neoclassical growth model to account for differences in aggregate labor productivity, most notably Mankiw, Romer and Weil (1992) and Chari, Kehoe and McGrattan (1996). The novelty of our approach is the emphasis on agriculture. We show that accounting for labor shares and productivity in agriculture is essential for understanding aggregate labor productivity differences across countries. Although a vast development literature addresses the role of agriculture in development, ${ }^{8}$ we contribute to this literature by quantifying the large effects of agriculture on the aggregate economy and the importance of TFP and barriers to using modern intermediate inputs in agriculture.

Our paper is also related to a recent literature that uses growth models to examine the process of structural transformation. ${ }^{9}$ These studies, however, do not explain the large disparities in agricultural labor productivity across countries. Three papers by Gollin, Parente and Rogerson (2000, 2001, and 2002) are most closely related to our research. Their first

\footnotetext{
${ }^{8}$ The development literature is too vast to cite here. See Johnson (1997) for a recent statement about the importance of agriculture in development.

${ }^{9}$ See Matsuyama (1992), Goodfriend and McDermott (1995), Echevarria (1997), Love (1997), Lucas (1998 and 2000), Hansen and Prescott (2002), Laitner (1998), Kongsamut, Rebelo and Xie (2001), Ngai (2000), Eswaran and Kotwal (2001), Stokey (2001), Caselli and Coleman (2001) and Yang and Zhu (2001).
} 
paper seeks to account for cross-country differences in agricultural labor productivity by unmeasured labor input and output in home production, and the other two papers argue that agricultural productivity determines the timing of industrialization and therefore is an important determinant of a country's aggregate output per worker today. Our paper is different from but complementary to their research in that we focus on current total factor productivity differences and barriers to using modern intermediate inputs in accounting for international differences in agricultural labor shares and productivity.

The rest of the paper is organized as follows. Section 2 presents the two-sector model that sets the basis for our quantitative analysis. Section 3 uses a simple analytical example to illustrate how barriers to using modern intermediate inputs in agriculture affect sectoral labor allocation and agricultural productivity. In Section 4 we explain how we calibrate our model and measure barriers to intermediate input use, and then present our quantitative results. Section 5 discusses several issues about agriculture that we have abstracted from and Section 6 concludes.

\section{The Two-Sector Model}

\section{A. Economic Environment}

Consider a two-sector model with the production and consumption of two goods, agricultural and nonagricultural. The production technologies in the two sectors take the Cobb-Douglas form, and consumption preferences are non-homothetic with a subsistence food requirement. The basic structure and variants of this model are used extensively in the agricultural de- 
velopment literature. ${ }^{10}$

We posit the following agricultural production function,

$$
Y_{a}=\left(\kappa A Z^{1-\sigma} L_{a}^{\sigma}\right)^{1-\alpha} X^{\alpha}, \quad 0<\sigma<1, \quad 0<\alpha<1, \quad \kappa>0
$$

where $Y_{a}, Z, L_{a}$, and $X$ refer to agricultural output, land, labor, and nonagricultural intermediate input, which may consist of chemical fertilizers, pesticide, fuel, energy and other purchased inputs. While $\kappa$ is a productivity parameter that is specific to the agricultural sector and takes the same value for all countries, $A$ is a parameter related to economy wide TFP and its value may vary from country to country. Both parameters are assumed to be exogenous. The non-agricultural production function is,

$$
Y_{n}=A L_{n}
$$

where $Y_{n}$ is nonagricultural output and $L_{n}$ is labor input. Accordingly, the subscript $a$ denotes the agricultural sector and $n$ denotes the nonagricultural sector.

Land in this economy is in fixed supply. Due to this constraint, labor input in agriculture exhibits decreasing returns, different from the nonagricultural sector. Note that as much as we would like to analyze the role of capital in affecting labor productivity, this input is omitted in both production functions. Because neither the Penn World Tables nor the agricultural data from FAO contain by-sector information on the capital stock, this pre-

\footnotetext{
${ }^{10}$ See Hayami and Ruttan (1985) and Mundlak (2000 and 2001) for discussions and empirical justification of the functional form assumption and other properties of the framework.
} 
cludes the possibility of incorporating capital in our quantitative analysis. In the Appendix, we introduce capital into the model and argue that, under rather general conditions, this omission does not affect our main results in any important way.

The production formulations above have two noticeable features that differ from a standard two-sector model. First, we include an intermediate input $(X)$ as a productive factor in agriculture. This formulation is motivated by the fact we discussed in the introduction that intermediate input use varies systematically with development in the cross-country data. For the production of this intermediate input, we assume that each unit of nonagricultural output can be converted into $1 / \pi$ units of $X$. Therefore, a low value of $\pi$ is associated with high efficiency of producing the input. Second, the TFP parameter $A$ affects productivity in both sectors. This specification attempts to capture the fact that factors influencing TFP, such as the state of scientific knowledge, market institutions, property rights, public infrastructure, and government policies, tend to have economy wide impact. Therefore, the efficiency in agricultural production is linked with that in nonagricultural production.

The economy is populated by a large and constant number (mass $N$ ) of homogeneous households who derive utility from consuming an agricultural good $\left(c_{a}\right)$ and a nonagricultural good $\left(c_{n}\right)$. The representative household's preferences are summarized by the following utility function,

$$
U=a \log \left(c_{a}-\bar{a}\right)+(1-a) \log \left(c_{n}\right),
$$

where $\bar{a}$ is the subsistence level of agricultural good consumption, and $a$ is an utility weight over the two goods. Let the nonagricultural good be the numeraire and $p_{a}$ be the price of 
the agricultural good. The utility function implies that the representative household first allocates $\bar{a}$ amount of income on the agricultural good, and then allocates the remaining income proportionally to the agricultural and nonagricultural goods. More specifically,

$$
\begin{aligned}
c_{a} & =\bar{a}+a p_{a}^{-1}\left(y-p_{a} \bar{a}\right), \\
c_{n} & =(1-a)\left(y-p_{a} \bar{a}\right) .
\end{aligned}
$$

Here, $y$ is the household's income.

\section{B. Barriers to Intermediate Input Use}

As we discussed in the introduction, there are two sources of barriers that may jeopardize the efficient use of agricultural intermediate input. First, we consider direct barriers in the market for $X$ that in effect increases $\pi$, the cost of converting nonagricultural output into the intermediate input. Hence, a high value of $\pi$ is interpreted as a high level of direct barriers faced by farmers in using this input. Second, we examine distortions in the labor market that in effect increases the cost of reallocating labor from agriculture to nonagriculture. We represent this cost as a constant proportion of the wage in the nonagricultural sector, $\theta w_{n}$. The no-arbitrage condition in the labor market implies that

$$
w_{a}=(1-\theta) w_{n}
$$

So, distortions in the labor market suppress wages in agriculture relative to wages in nonagriculture, giving farmers incentive to substitute labor input for intermediate input. 


\section{Definition of Equilibrium}

A competitive equilibrium is a set of allocations $\left\{L_{a}, L_{n}, c_{a}, c_{n}, X\right\}$, prices $\left\{p_{a}, w_{a}, w_{n}\right\}$, and profits for agricultural firms, such that: (i) Given prices and profits, $c_{a}, c_{n}$ solve the household's utility maximization problem; (ii) Given prices, $L_{a}, X$, and $L_{n}$ solve the firms profit maximization problems in each sector; (iii) Condition (3) holds so that households are indifferent between working in the two sectors; and (iv) All markets clear, i.e.,

$$
\begin{aligned}
N & =L_{a}+L_{n}, \\
Y_{a} & =N c_{a}, \\
Y_{n} & =N c_{n}+\pi X .
\end{aligned}
$$

\section{Effects of Barriers: An Analytical Illustration}

Before conducting quantitative exercises, we first examine analytically why barriers to intermediate input use tend to reduce labor productivity and therefore raise the labor share in agriculture.

Using the production function for agricultural output, we can decompose output per worker in agriculture as follows,

$$
\frac{Y_{a}}{L_{a}}=\kappa A\left(\frac{Z}{N}\right)^{1-\sigma}\left(\frac{X}{Y_{a}}\right)^{\frac{\alpha}{1-\alpha}}\left(\frac{L_{a}}{N}\right)^{\sigma-1}
$$

where $N$ is the population size. Recall that the subsistence food requirement is a key feature 
of the model. In this section, in order to simplify the exposition, we consider a special case when $a=0$. That is, the demand for agricultural output is determined solely by the population's subsistence consumption of the agricultural good. Then, under this assumption, market clearing in the agricultural output market requires $Y_{a}=N \bar{a}$, where $\bar{a}$ is the per capita subsistence food consumption, and the labor share and productivity in agriculture are given by,

$$
\begin{aligned}
\frac{L_{a}}{N} & =\left(\frac{\bar{a}}{\kappa A\left(\frac{Z}{N}\right)^{1-\sigma}\left(\frac{X}{Y_{a}}\right)^{\frac{\alpha}{1-\alpha}}}\right)^{1 / \sigma}, \\
\frac{Y_{a}}{L_{a}} & =\left(\frac{\kappa A\left(\frac{Z}{N}\right)^{1-\sigma}\left(\frac{X}{Y_{a}}\right)^{\frac{\alpha}{1-\alpha}}}{\bar{a}^{1-\sigma}}\right)^{1 / \sigma} .
\end{aligned}
$$

Hence, the model implies that low agricultural productivity requires a high labor share in farming in order to satisfy the subsistence requirement, regardless of the sources of low productivity in agriculture. In our setting, low productivity in agriculture can be generated by low overall TFP $A$, low land to population ratio $Z / N$, low intensity of intermediate input use $X / Y_{a}$, and low relative productivity of the agricultural technology $\kappa$. Moreover, the labor force required in agriculture to satisfy subsistence food demand increases with the degree of decreasing returns to labor in the agricultural production function (measured by $\sigma$ ) for a given level of productivity.

Equations (8) and (9) also show that the intermediate input to output ratio, $X / Y_{a}$, is positively related to agricultural labor productivity and negatively related to the share of labor in agriculture, consistent at least qualitatively with the evidence presented in the intro- 
duction. The remaining question is: What factors determine farmers' choice of intermediate inputs in agricultural production? To answer this question, consider the profit maximization problem of a representative farmer,

$$
\max _{X, L_{a}}\left\{p_{a}\left(\kappa A Z^{1-\sigma} L_{a}^{\sigma}\right)^{1-\alpha} X^{\alpha}-\pi X-w_{a} L_{a}\right\},
$$

where $p_{a}$ is the price of the agricultural good relative to the non-agricultural good, $\pi$ is the proportional cost paid by farmers at the farm gate for $X$, and $w_{a}$ is the wage in the agricultural sector. The first order condition with respect to the intermediate input implies that

$$
X=\left(\frac{\alpha p_{a}}{\pi}\right)^{\frac{1}{(1-\alpha)}} \kappa A Z^{1-\sigma} L_{a}^{\sigma}
$$

Substituting this equation into the agricultural production function we obtain

$$
Y_{a}=\left(\frac{\alpha p_{a}}{\pi}\right)^{\frac{\alpha}{(1-\alpha)}} \kappa A Z^{1-\sigma} L_{a}^{\sigma}
$$

So, taking prices as given, the optimal intermediate input to output ratio for the representative farmer is given by

$$
\frac{X}{Y_{a}}=\alpha \frac{p_{a}}{\pi}
$$

That is, the intensity of the intermediate input use is determined by its share in production function, $\alpha$, and the price of the agricultural good relative to the cost of the intermediate input.

If we continue to assume that agricultural output is used solely for subsistence consump- 
tion, we can solve for the equilibrium level of agricultural price $p_{a}$ that clears the market (see the Appendix). Substituting the equilibrium price into the equation above, we obtain,

$$
\frac{X}{Y_{a}}=\left(\frac{\mu w_{a}^{\sigma}}{\pi^{\sigma} \kappa A\left(\frac{Z}{N}\right)^{1-\sigma}}\right)^{\frac{(1-\alpha)}{1-(1-\alpha)(1-\sigma)}},
$$

where $\mu$ is a constant given by $\mu=\bar{a}^{1-\sigma}\left(\frac{\alpha}{\sigma(1-\alpha)}\right)^{\sigma}$.

Equation (10) suggests two potential reasons for the low intensity of $X$ in poor countries where distortions are acute: high costs of the intermediate input, $\pi$ and low agricultural wage, $w_{a}$. As we discussed in the introduction, factors contributing to the high cost of the intermediate input include government protection of domestic industry and lack of investment in necessary infrastructures such as road and distribution systems, and factors contributing to low agricultural wage may vary from institutional protection of industrial wages and labor mobility restrictions to poor information flows that raise the costs of migration. In section 4, we show that there are systematic differences in the relative price of intermediate inputs and in the relative wage between agricultural and non-agricultural sectors across poor and rich countries.

We would like to emphasize that the use of the intermediate input is a key mechanism through which the direct and indirect barriers $(\pi, \theta)$ realize their effects on the labor share and productivity in agriculture. This can be demonstrated clearly in equations (8) and (9), by setting $\alpha=0$. Without the intermediate input in agricultural production, distortions in the relative price of $X$ and in labor markets would have no impact on sectoral labor allocation and productivity. 


\section{Quantitative Analysis}

In this section we assess the quantitative role of total factor productivity $A$ and barriers to using intermediate inputs $(\pi, \theta)$ in generating the observed cross-country patterns in the agricultural labor share, the intermediate input to output ratio in agriculture, and the agricultural and aggregate labor productivity. We assume countries are otherwise identical but in TFP and barriers. We find that the model with these exogenous differences can account for a large portion of the observed differences in the labor share and productivity across countries.

\subsection{Calibration}

We calibrate our benchmark economy to the 1985 U.S. data. The following 7 parameter values need to be determined: $a, \bar{a}, \alpha, \sigma, Z / N, A$, and $\kappa$.

The land to population ratio $Z / N$ is taken directly from the U.S. data. The ratio of arable land (in hectares) per working age person in the U.S. economy is 1.8. The technology parameters $(A, \kappa)$ are chosen from sectoral residual calculations for the U.S. economy using the production functions specified in the previous section, which results in $A=34,254$ and $\kappa=0.49$.

The labor income share in agriculture $\sigma$ is set at 0.7 , consistent with the estimates of agricultural production functions reported by Hayami and Ruttan (1985) and Mundlak (2001). The elasticity parameter of intermediate inputs in agricultural output $\alpha$ is chosen to match the intermediate input to output ratio in the U.S. economy. This implies $\alpha=0.4$. 
Finally, the values of preference parameters $a$ and $\bar{a}$ are selected to match two targets for the agricultural labor share. Roughly speaking, $a$ determines the long-run share of labor in agriculture and $\bar{a}$ determines a given labor share in agriculture away from its long-run value. We assume a long-run agricultural labor share of $0.5 \%$. The labor share in agriculture for the U.S. economy in 1985 is $3.2 \%$. These targets imply $a=0.005$ and $\bar{a}=839$. Notice that our choice for the long-run share of labor in agriculture is somewhat arbitrary, ${ }^{11}$ however, several papers in the related literature (e.g. Caselli and Coleman, 2001; and Gollin, Parente, and Rogerson, 2001 and 2002) have assumed either a share of zero or a lower share than the one we use. It turns out that assuming lower values for the long-run share of labor in agriculture would strengthen our quantitative results.

A summary of the calibrated parameter values and targets is provided in Table 1 .

Table 1: Calibration of Parameter Values to U.S. Data

\begin{tabular}{ccl} 
Parameter & Value & Target \\
\hline$Z / N$ & 1.8 & Land to population ratio \\
$A$ & 34,254 & Labor productivity in non-agriculture \\
$\kappa$ & 0.49 & Agricultural productivity index \\
$\sigma$ & 0.7 & Hayami and Ruttan 1985 \\
$\alpha$ & 0.4 & Intermediate input share \\
$a$ & 0.005 & Long-run agricultural labor share \\
$\bar{a}$ & 839 & Labor share in agriculture \\
\hline
\end{tabular}

\subsection{Measuring Barriers to Intermediate Input Use}

\section{A. Direct Barriers ( $\pi$ )}

\footnotetext{
${ }^{11}$ The share of labor in agriculture in the U.S. economy has continued to fall to less than $2 \%$ in the 90 's.
} 
The FAO data provides information on the prices paid by farmers (at the farm-gate) for intermediate nonagricultural inputs used in agricultural production (such as pesticides, fertilizers, fuel and energy, electricity and other miscellaneous items). Roughly speaking these purchasing power parity prices are the ratio of expenditures in these items relative to the quantity of intermediate inputs priced at international prices. We use the price of nonagricultural output as the numeraire (following the set up in our model) and compute the relative price of intermediate inputs relative to the nonagricultural output for each country. These prices are reported in Figure 3. There are important differences in relative intermediate input prices and the differences are systematically related to development. For instance, Ethiopia, Nepal, and Mali report relative prices of intermediate inputs that are factors of 6 and 7 of the U.S. relative price. We interpret these relative price differences as a measure of direct barriers to using intermediate inputs, $\pi$. Jones (1994) and Restuccia and Urrutia (2001) have used the price of investment relative to consumption as a measure of barriers to investment in one-sector growth models.

\section{B. Indirect Barriers $(\theta)$}

In an environment with perfect labor mobility, wages must be equalized across sectors. As we suggested in section 3, low wages in the agricultural sector relative to the nonagricultural sector may account for the low intensity with which farmers utilize intermediate inputs in poor countries. We investigate this possibility by constructing measures of sectoral wages across countries using the no-arbitrage condition for relative wages in equation $(3), w_{a}=$ $(1-\theta) w_{n}$. Because there is no readily available data set that provides comparable sectoral wages for a large sample of countries, we use the average product of labor in nonagriculture 
as a proxy for the wage in that sector, and use the relative price of agricultural good times

the average product of labor in agriculture as a proxy for the agricultural wage. ${ }^{12}$ As long as labor income shares are constant across countries, as suggested by the evidence in Gollin (2002), relative barriers should not be affected by the labor share in agricultural production. ${ }^{13}$ We find large and systematic differences in indirect barriers in the labor market across countries. ${ }^{14}$ These are illustrated in Figure 4.

\subsection{Quantitative Results}

We assume that countries are otherwise identical to the benchmark economy except in their TFP parameter $A$ and barriers to using intermediate inputs $(\pi, \theta) .{ }^{15}$ Differences in TFP and barriers are taken exogenously. Differences in TFP are calibrated to labor productivity differences in the nonagricultural sector as described in Figure 1 and differences in barriers are calibrated to differences in the relative price of intermediate inputs and in relative wages between the agricultural and nonagricultural sectors, as documented in Figures 3 and $4 .{ }^{16}$ For

\footnotetext{
${ }^{12}$ Our model-based construction of the labor market distortion index is very similar to the methodology used by Mulligan (2002a and 2002b) and Chari, Kehoe and McGrattan (2002a and 2002b), where these authors use first order conditions to back out the implied distortions in the labor market.

${ }^{13}$ We use data from FAO and Summers and Heston (1991) on the relative price of agriculture and relative labor products in international prices to construct our measure of indirect barriers. Similar magnitudes of barriers are obtained if instead, direct measures of labor products in domestic prices are used.

${ }^{14}$ While we emphasize in this paper the role of labor market distortions in generating the wage gap between the two sectors, another potentially important reason for the wage gap is the difference in average skill level of workers between the two sectors (see Caselli and Coleman, 2001). However, no matter what the source is, the wage gap necessarily implies lower labor cost in agriculture and therefore less incentive for farmers to use intermediate inputs.

${ }^{15}$ Economies also differ on the land to population ratio $Z / N$, but as we document in Table 2, the large differences in this statistic across countries are not systematically related to development and hence contribute little to agricultural labor productivity differences (roughly $1.9 \%$ of the variation in labor productivity in agriculture across countries).

${ }^{16}$ In this paper, we focus on agricultural productivity differences, taking non-agricultural productivity differences as given. There is a large literature dealing with aggregate productivity differences, with emphasis on capital accumulation and total factor productivity. See, for example, McGrattan and Schmitz (1999) and
} 
every country in our sample, the equilibrium labor share in agriculture, the labor productivity in agriculture and in aggregate are computed. In comparing aggregate labor productivity we use the relative price of agriculture in the benchmark economy. Similar results are obtained if instead a geometric average of relative prices is used as the international price of agriculture.

\section{A. Labor Share and Productivity in Agriculture}

The quantitative results of our experiment are striking. Figure 5 reports the results of this exercise for the labor share, the intermediate input to output ratio in agriculture, and aggregate labor productivity. In this figure, the first panel reports the agricultural labor share in the model and the data. The model implies agricultural labor shares that are as high as those observed in the data. The second panel displays the intermediate input to output ratio in the model and the data. The model generates intermediate input to output ratios that are as low as those observed in the data for poor countries. The third panel displays the aggregate labor productivity differences relative to the benchmark economy in the model and the data. The model generates very low aggregate labor productivity as observed in the poorest countries. These results illustrate the importance of the subsistence constraint on agricultural goods when countries are faced with low TFP levels and barriers to intermediate inputs.

In order to summarize the results of the model, we follow Klenow and Rodriguez-Clare (1997) and calculate the percentage of variation in each variable of interest in the data that is accounted for by the model. The results of these calculations are reported in the first column of Table 2. As suggested by Figure 5, the model accounts for a large fraction of the variation

Parente and Prescott (2000) for excellent surveys of this literature. 
in each variable of interest. For instance, the model accounts for $87 \%$ of the variation in the share of labor allocated to the agricultural sector across countries. The model with barriers to intermediate input use (both direct and indirect) accounts for $79 \%$ of the variation in the intermediate input to output ratio across countries. By way of generating large labor shares in agriculture and low intermediate input use in poor countries, the model also accounts of a large portion of labor productivity differences in agriculture (64\%) and aggregate output per worker differences (89\%) across countries.

Table 2: Percentage of Variation Accounted by the Model

\begin{tabular}{|l|cccc|}
\hline & \multicolumn{4}{|c|}{ Model Specification } \\
Variable Explained & $\frac{(1-\theta)}{\pi}$ & $\pi$ & $(1-\theta)$ & No Barriers \\
\hline$L_{a} / N$ & 86.6 & 57.4 & 70.6 & 40.7 \\
$X / Y_{a}$ & 79.1 & 24.6 & 32.6 & -21.5 \\
$Y_{a} / L_{a}$ & 64.2 & 43.1 & 54.8 & 33.6 \\
$Y / N$ & 89.4 & 62.4 & 62.9 & 56.3 \\
\hline Decomposition of $Y_{a} / L_{a}$ by & & & & \\
$\left(X / Y_{a}\right)^{\frac{\alpha}{(1-\alpha)}}$ & 17.2 & 2.4 & 10.2 & -4.0 \\
$(Z / N)^{1-\sigma}$ & 1.9 & 1.9 & 1.9 & 1.9 \\
$\left(L_{a} / N\right)^{\sigma-1}$ & 18.3 & 11.9 & 15.9 & 9.3 \\
$A$ & 26.8 & 26.8 & 26.8 & 26.8 \\
\hline
\end{tabular}

The lower portion of Table 2 reports additional information on the decomposition of contributing factors to agricultural productivity $\left(Y_{a} / L_{a}\right)$. The results show that both TFP and intermediate input to output ratio have positive effects on labor productivity in agriculture. The agricultural labor share has a negative effect on labor productivity due to decreasing returns to labor in farming.

\section{B. The Role of Barriers}

Both direct and indirect barriers to using intermediate inputs, namely the cost of using 
intermediate inputs and barriers to labor mobility, are important in accounting for the intermediate input to output ratio differences observed in the data. When the model is computed by considering each barrier at a time, $25 \%$ and $33 \%$ of the variation in the intermediate input to output ratio across countries are accounted for by the model (See columns 2 and 3 in Table 2). When the effects of both barriers are included, the model accounts for $79 \%$ of the variation (column 1). Moreover, when barriers are not included in the model (column 4), the intermediate input to output ratio implied by the model is negatively related to the observed in the data. In the absence of barriers, the model implies that countries with high TFP would use intermediate inputs less intensively. As long as intermediate inputs are important in agricultural production, this prediction of the theory limits alternative theories of agricultural labor productivity differences across countries that rely solely on TFP differences.

\section{The Role of TFP and Intermediate Inputs}

To understand the relative contribution of TFP and intermediate inputs in accounting for the labor share and labor productivity, we calculate the percentage of variance in each variable that is accounted for by the model in the case where barriers are chosen to reproduce the observed $X / Y_{a}$ in each country. This version of the model accounts for $78 \%$ of the differences in the agricultural labor share, $60 \%$ of the differences in agricultural productivity, and $93 \%$ of the differences in aggregate labor productivity. (See the first column in Table 3.) To isolate the role of TFP, we eliminate the contribution of intermediate inputs by setting its

share to zero $(\alpha=0)$. The model without intermediate inputs accounts for $48 \%$ of the labor share differences, $40 \%$ of the agricultural productivity differences, and $58 \%$ of the aggregate 
productivity differences. These results strongly suggests the importance of understanding low TFP and low intermediate input use in agriculture in poor countries.

Table 3: Percentage of Variation Accounted by TFP and Intermediate Inputs

\begin{tabular}{|l|cc|}
\hline & \multicolumn{2}{|c|}{ Model Specification } \\
Variable Explained & $X / Y_{a}$ & $\alpha=0$ \\
\hline$L_{a} / N$ & 78.1 & 47.5 \\
$X / Y_{a}$ & 100.0 & 0.0 \\
$Y_{a} / L_{a}$ & 59.6 & 39.6 \\
$Y / N$ & 92.6 & 58.2 \\
\hline Decomposition of $Y_{a} / L_{a}$ by & & \\
$\left(X / Y_{a}\right)^{\frac{\alpha}{(1-\alpha)}}$ & 14.8 & 0.0 \\
$(Z / N)^{1-\sigma}$ & 1.9 & 1.9 \\
$\left(L_{a} / N\right)^{\sigma-1}$ & 16.1 & 10.9 \\
$A$ & 26.8 & 26.8 \\
\hline
\end{tabular}

\section{Amplification Effect}

The role of agriculture in the economy amplifies the aggregate impact of TFP differences across countries. Compared with a one-sector growth model where output is produced with the nonagricultural technology only and using the same exogenous variation of TFP levels across countries, the model with agriculture is able to account for twice the variation in aggregate labor productivity, that is, TFP differences alone account for $44 \%$ of the variability in aggregate labor productivity in a one-sector version of our model. Incorporating agriculture in the environment improves the model's implication in this statistic to $89 \%$. Moreover, looking at the range of variation between the 5 richest and poorest countries, the model implies aggregate labor productivity differences of factors of 22 , while a one-sector version of our model with non-agriculture only would imply labor productivity differences of factors of 4 , that is, the model with agricultural production amplifies aggregate productivity 
differences by a factor of 5 between the richest and poorest countries.

\subsection{Sensitivity Analysis}

Two features of the agricultural production function in our environment are important for our quantitative results: the income share of intermediate inputs $\alpha$ and the land share $(1-\sigma)$.

Our benchmark results are based on what we consider reasonable values of these parameters. However, in the agricultural development literature, empirical studies report various estimates of these parameters, which may deviate from the values we used. To evaluate the sensitivity of our results to different parameter values, we consider an alternative set of values: $\alpha=0.2$ (intermediate inputs contribute a smaller factor share), and $\sigma=0.9$ (a lower land share and therefore smaller degree of decreasing returns to labor) ${ }^{17}$ recalling that our calibrated values are $\alpha=0.4$ and $\sigma=0.7$. The results in Table 4 show that reducing $\alpha$ or increasing $\sigma$ would reduce the contribution of the model in understanding aggregate income differences. Although the model is still able to generate a large variability in labor shares in agriculture across countries, a large portion of agricultural labor productivity would be unaccounted for and this reduces the extent to which the model can account for aggregate labor productivity differences. However, under these extreme parameter value assumptions, the role of agriculture is still important in understanding aggregate labor productivity differences.

Our results are also based on the assumption that the TFP parameter $A$ enters linearly in

\footnotetext{
${ }^{17}$ These parameter values can be considered as a lower bound for $\alpha$ and a high bound for $\sigma$; see Mundlak (2001) for related discussions and summary reports. Note that the factor share $\alpha$ in our analysis should not only include the contribution of fertilizers but also pesticides, processed seeds, fuel, electricity, and other purchased intermediate inputs for agricultural production.
} 
Table 4: Percentage of Variation Accounted by the Model with Alternative Parameter Values

\begin{tabular}{|l|ccc|}
\hline & \multicolumn{3}{|c|}{ Model Specification } \\
Variable Explained & Benchmark & $\alpha=0.2$ & $\sigma=0.9$ \\
\hline$L_{a} / N$ & 86.6 & 73.5 & 77.9 \\
$X / Y_{a}$ & 79.1 & 111.0 & 105.1 \\
$Y_{a} / L_{a}$ & 64.2 & 53.7 & 55.8 \\
$Y / N$ & 89.4 & 67.3 & 62.8 \\
\hline Decomposition of $Y_{a} / L_{a}$ by & & & \\
$\left(X / Y_{a}\right)^{\frac{\alpha}{(1-\alpha)}}$ & 17.2 & 9.1 & 22.8 \\
$(Z / N)^{1-\sigma}$ & 1.9 & 1.9 & 0.6 \\
$\left(L_{a} / N\right)^{\sigma-1}$ & 18.3 & 15.9 & 5.5 \\
$A$ & 26.8 & 26.8 & 26.8 \\
\hline
\end{tabular}

the agricultural production function. We evaluate the importance of this linearity assumption by specifying a more general production function of agricultural goods where the TFP parameter enters non-linearly. In particular, we assume the following agricultural production function

$$
Y_{a}=\left(\kappa A^{\phi} L_{a}^{\sigma} Z^{1-\sigma}\right)^{1-\alpha} X^{\alpha}
$$

where $0<\phi<\infty$. This production function is identical to the one described before except for the parameter $\phi$. For parameter values of $\phi>1$, the impact of TFP on agricultural productivity is larger than on non-agricultural productivity, and can be motivated by the difficulties of implementing or adopting efficient production techniques in countries with varied climate/soil conditions or with varied human capital endowments. Parameter values of $\phi<1$ might be motivated by partial substitutability techniques (appropriate technology) or by low reproducible capital shares in agricultural production. ${ }^{18}$ The results of this exercise are summarized in Table 5. The main conclusion from this table is that small departures

\footnotetext{
${ }^{18}$ For more extensive discussions of the role of capital in our model please see the Appendix.
} 
from our linear assumption regarding how TFP differences affect each sector would not alter the main quantitative results of the paper.

Table 5: Percentage of Variation Accounted by the Model with Non-linearity in A

\begin{tabular}{|l|ccc|}
\hline & \multicolumn{3}{|c|}{ Model Specification } \\
Variable Explained & Benchmark & $\phi=0.9$ & $\phi=1.1$ \\
\hline$L_{a} / N$ & 86.6 & 84.3 & 88.5 \\
$X / Y_{a}$ & 79.1 & 86.4 & 72.0 \\
$Y_{a} / L_{a}$ & 64.2 & 62.4 & 66.0 \\
$Y / N$ & 89.4 & 81.3 & 97.0 \\
\hline Decomposition of $Y_{a} / L_{a}$ by & & & \\
$\left(X / Y_{a}\right)^{\frac{\alpha}{(1-\alpha)}}$ & 17.2 & 18.4 & 16.0 \\
$(Z / N)^{1-\sigma}$ & 1.9 & 1.9 & 1.9 \\
$\left(L_{a} / N\right)^{\sigma-1}$ & 18.3 & 17.9 & 18.6 \\
$A$ & 26.8 & 24.1 & 29.5 \\
\hline
\end{tabular}

\section{Discussion}

Our world economy consists of a set of closed economies. Given the large and systematic differences in agricultural labor productivity across countries, an important question is the role of trade in mitigating these differences. The evidence suggests that there is not a lot of imports of food products in the very poor countries, so why aren't poor countries importing food? A possible explanation has to do with prices of food and distribution systems in poor countries. Using the 1985 ICP benchmark price data contained in the Penn World Tables we calculate the price of food (at market exchange rates). We find that the price of food is higher in rich than in poor countries. However, the price of agricultural products (at the farm gate) is no higher in rich than in poor countries. (For a documentation of 
these observations see Figure 6.) One possible explanation for these price observations across countries is that food prices include distribution and marketing services. The U.S. Department of Agriculture reports that for every dollar spent on food, only 20 cents go to the farmer and the remaining 80 cents go to distribution and marketing charges. ${ }^{19}$ While the complete set of service charges may not be required for imports to poor countries, lack of access to efficient distribution systems in those countries may prevent rural areas to benefit from the imports of food products.

Our analysis has abstracted from the potential role of mismeasurement in the labor input and output in agriculture. While FAO is the best data available for international comparisons of agricultural output as it constructs measures of output from production not expenditures on food (since most of the agricultural production is not transacted in a market place in the very poor countries), agricultural output is more difficult to measure in the very poor countries. Moreover, the labor input in agriculture may be mismeasured. For example, a rural worker that works a few hours in the farm and most hours in other activities may be counted as an agricultural worker. However, we argue that the productivity differences in agriculture are so substantial that it is unlikely that mismeasurements of output and inputs would erase all these differences. ${ }^{20}$

We have also abstracted from technology choice in agriculture. Poor countries may be using traditional agricultural technologies such that the marginal contribution of intermediate

\footnotetext{
${ }^{19}$ See Adamopoulos (2003) for preliminary work on the role of the distribution sector in explaining the cross-country price observations.

${ }^{20}$ Notice that our model accounts for about $50-60 \%$ of the observed cross-country differences in agricultural labor productivity.
} 
inputs is low. ${ }^{21}$ In the Appendix we argue that adding a traditional agricultural technology to our environment where intermediate inputs are not important would reinforce our quantitative results. The reason is that barriers to intermediate input use would prevent the choice of modern agricultural technologies in detriment of productivity.

\section{Conclusion}

In this paper we show that a large portion of the cross-country labor productivity differences in agriculture (and in the aggregate) is accounted for by a simple two-sector general equilibrium model with subsistence food requirements and decreasing returns to labor in agricultural production that features TFP differences and barriers to using intermediate inputs in agriculture. Our emphasis on the role of agriculture in development has a long tradition in the development economics literature. We contribute to this literature by quantifying the role of agriculture in the aggregate economy and analyzing the importance of TFP and barriers to intermediate inputs in generating labor productivity and labor share differences in agriculture across countries. By accounting for an important portion of the international differences in agricultural labor share and productivity, this paper provides a better understanding of aggregate productivity differences across countries.

Our results suggest a greater emphasis in understanding TFP differences across countries as advocated by the work of Prescott (1998), Parente and Prescott (2000), Hall and Jones (1999), and Klenow and Rodriguez-Clare (1997). In our model relatively small differences

\footnotetext{
${ }^{21}$ Caselli and Coleman (2003) have studied appropriate technology in a cross section of countries.
} 
in TFP translates into very large aggregate labor productivity differences across countries. Our results suggest that the TFP differences needed to account for the wealth of nations today are much smaller once the role of agriculture in development is taken into account.

Our analysis also highlights the cost of government policies that systematically discriminate against agriculture. These policies create factor market distortions that reduce the incentives for farmers in poor countries to use modern inputs that are crucial for improving agricultural productivity. These are the same problems that T.W. Schultz (1964) analyzed almost forty years ago in his influential work, "Transforming Traditional Agriculture." Unfortunately, our quantitative analysis shows that for many countries in the world, barriers to transforming traditional agriculture are still pervasive. These barriers need to be removed before a significant improvement of agricultural and aggregate productivity can be seen in these countries. 


\section{A Data for Agriculture}

This appendix explains the construction of agricultural output statistics. A complete description of these procedures is in Prasada Rao (1993). The main source of data is the Food and Agricultural Organization of the United Nations (FAO).

Due to data limitations, agricultural activities include agriculture and hunting but excludes forestry and fishing. Within agricultural activities, only crops and livestock production is included because the lack of reasonable cross-country data for agricultural services. Output is comprised of a large and representative set of commodities, and aggregation is

done using prices. The FAO data have an important advantage: agricultural production is valued at producer prices, that is, using farm-gate prices that exclude expenses such as costs of transportation, distribution and marketing.

Using data of $N$ commodities, indexed by $i$, and $M$ countries, indexed by $j$, total agricultural output in country $j$ is defined as,

$$
T_{j}=\sum_{i=1}^{N} p_{i, j} q_{i, j},
$$

where $q_{i, j}$ and $p_{i, j}$ are the quantity and price of commodity $i$ in country $j$. Hence, this is a measure of total output in country $j$ prices (currency). In order to obtain comparable measures of agricultural total production across countries, a common set of prices must be used. Let $\pi_{i}$ be the international price of commodity $i$ measured in a reference currency (dollars), therefore, total agricultural output in country $j$ at international prices is defined as,

$$
T_{j}^{*}=\sum_{i=1}^{N} \pi_{i} q_{i, j} .
$$

There are two important measures of agricultural output considered: final output and GDP. Final output comprises total output as defined above minus any intermediate agricultural inputs used in production such as feed and seed. GDP consists of final output minus any intermediate nonagricultural inputs, such as fertilizer, pesticide, fuel and energy. Therefore, 
agricultural final output, $F_{j}$, is defined as,

$$
F_{j}=\sum_{i=1}^{N} p_{i, j} q_{i, j}-\sum_{i=1}^{N} p_{i, j}^{s} s_{i, j}-\sum_{i=1}^{N} p_{i, j}^{f} f_{i, j}
$$

where $s_{i, j}$ is the quantity of commodity $i$ used as seed and $f_{i, j}$ is the quantity of commodity $i$ used as feed. Notice that the prices of these inputs are allowed to differ from the producer price, that is, the general principle is that all prices are valued at the farm-gate, and therefore, prices for inputs are the purchase price paid by farmers at the farm-gate including any distribution charges, such as transportation costs, and any taxes, subsidies and/or bulk discounts. Agricultural GDP is defined as,

$$
Y_{j}=F_{j}-\sum_{k=1}^{K} w_{k, j} x_{k, j}
$$

where $x_{k, j}$ and $w_{k, j}$ are the quantity and price of non-agricultural commodity $k$ in country j. Again, the general pricing principle is that $w_{k, j}$ is the farm-gate purchase price paid by the farmer.

Both final output and GDP are converted in comparable units across countries using standard methods. These are extensively described in Prasada Rao (1993) and the references therein. A general principle of these aggregation methods is the property of country invariance and transitivity, that is the results of these methods are independent of the political subdivision of the world and the comparison of two countries is not affected by the comparison through a third alternative country.

We present the basic aggregation procedure used, the Geary-Khamis (GK) method. This methods involves finding the fixed point of the following system of equations:

$$
\begin{aligned}
\pi_{i} & =\sum_{j=1}^{M}\left(\frac{p_{i, j}}{P P P_{j}}\right) \gamma_{i, j}, \\
P P P_{j} & =\frac{\sum_{i=1}^{N} p_{i, j} q_{i, j}}{\sum_{i=1}^{N} \pi_{i} q_{i, j}}
\end{aligned}
$$

where $\gamma_{i, j}=\frac{q_{i, j}}{\sum_{j=1}^{M} q_{i, j}}$ are quantity weights. The first $N$ equations correspond to the deter- 
mination of international prices for every commodity $i$, as a weighted average of prices in the world, and the remaining $M$ equations correspond to the determination of agricultural purchase power parities for every country $j$, as the ratio of output in domestic prices relative to output valued at international prices. A slightly different method is used to compute a comparable measure of agricultural GDP taking non-agricultural input prices into account.

The data is contained in the FAO Interlinked Computerized Storage and Purchasing System of Food and Agricultural commodities (ICS). The output data includes 185 commodities at a fairly detailed level (although it is not adjusted for quality differences), 58 commodities used as seed, and 146 commodities used as feed. Data on quantities and prices are collected for all benchmark years, 1970, 1975, 1980, 1985 and 1990. There are 103 countries in the sample, representing $99 \%$ of total world agricultural production and $98 \%$ of the world population. The sample of countries is fairly well distributed along the cross-country income distribution.

\section{B Solution of Equilibrium}

From the farm's profit maximization problem we have

$$
\begin{gathered}
X=\left(\frac{\alpha p_{a}}{\pi}\right)^{\frac{1}{(1-\alpha)}} \kappa A Z^{1-\sigma} L_{a}^{\sigma} \\
Y_{a}=\left(\frac{\alpha p_{a}}{\pi}\right)^{\frac{\alpha}{(1-\alpha)}} \kappa A Z^{1-\sigma} L_{a}^{\sigma},
\end{gathered}
$$

and

$$
\frac{X}{Y_{a}}=\alpha \frac{p_{a}}{\pi}
$$

From the labor market no-arbitrage condition (3), then, we have

$$
\sigma(1-\alpha) \alpha^{-1} \pi\left[\alpha p_{a} / \pi\right]^{1 /(1-\alpha)} \kappa Z^{1-\sigma} L_{a}^{\sigma-1}=(1-\theta)
$$


which implies that

$$
\frac{X}{Y_{a}}=\alpha \frac{p_{a}}{\pi}=\left[\frac{\alpha(1-\theta)}{\sigma(1-\alpha) \pi \kappa(Z / N)^{1-\sigma}}\right]^{1-\alpha} l_{a}^{(1-\alpha)(1-\sigma)}
$$

where $l_{a}=L_{a} / N$ is the share of labor in agriculture. Substituting (11) into (7) yields the following expression for the agricultural labor productivity:

$$
\frac{Y_{a}}{L_{a}}=A\left[\frac{\alpha(1-\theta)}{\sigma(1-\alpha) \pi}\right]^{\alpha}\left[\kappa\left(\frac{Z}{N}\right)^{1-\sigma}\right]^{1-\alpha} l_{a}^{-(1-\alpha)(1-\sigma)}
$$

From the household's consumption allocation equations (1) and (2), we have

$$
c_{a}=\bar{a}+\frac{a}{1-a} p_{a}^{-1} c_{n}
$$

Substituting the market clearing conditions (5) and (6) into the equation above, we have

$$
\frac{Y_{a}}{L_{a}} l_{a}=\bar{a}+\frac{a}{1-a} p_{a}^{-1}\left[A\left(1-l_{a}\right)-\frac{\pi X}{Y_{a}} \frac{Y_{a}}{L_{a}} l_{a}\right]
$$

Substituting $p_{a}=\alpha^{-1} \pi X / Y_{a}$ into the equation above yields the following:

$$
\left(1+\frac{a \alpha}{1-a}\right) \frac{Y_{a}}{L_{a}} l_{a}=\bar{a}+\frac{a \alpha}{1-a} \pi^{-1}\left(\frac{X}{Y_{a}}\right)^{-1} A\left(1-l_{a}\right) .
$$

From (10) and (12), then, we have

$$
\begin{aligned}
& {\left[1+\frac{a \alpha}{1-a}\right] A\left[\frac{\alpha(1-\theta)}{\sigma(1-\alpha) \pi}\right]^{\alpha}\left[\kappa\left(\frac{Z}{N}\right)^{1-\sigma}\right]^{1-\alpha} l_{a}^{1-(1-\alpha)(1-\sigma)} } \\
= & \bar{a}+\frac{a \alpha}{1-a} \pi^{-1}\left[\frac{\alpha(1-\theta)}{\sigma(1-\alpha) \pi \kappa(Z / N)^{1-\sigma}}\right]^{\alpha-1} l_{a}^{-(1-\alpha)(1-\sigma)} A\left(1-l_{a}\right),
\end{aligned}
$$

which is the equation that can be used to solve for the share of labor in agriculture, $l_{a}$. Once $l_{a}$ is solved, we can substitute it into equations (11) and (12) to solve for the intermediate input to output ratio and the agricultural labor productivity, respectively. Equation (10) in Section 3 is a special case of equation (11) when $a=0$. 


\section{The Role of Capital}

Our two-sector model abstracts from capital. We interpret that differences in labor productivity are due to differences in total factor productivity, which we assume to be constant across sectors but differ across countries. Our interpretation of technologies is conservative in the sense that the implementation or adoption of newer, more advanced technologies may be more difficult in agriculture for poor relative to rich countries. However, there is an alternative interpretation related to the role of capital in determining labor productivity differences across countries. In this appendix we add capital to our model to argue that our linearity assumption on total factor productivity across sectors roughly holds under plausible assumptions of technologies with capital input. In particular we find that as long as the capital share across technologies is roughly the same or as long as capital accumulation accounts for a smaller portion of labor productivity differences across countries, our linearity assumption is conservative in terms of total factor productivity differences across sectors.

Consider the following modification of the production functions for agriculture and nonagriculture expressed in per-worker form,

$$
y_{n}=\bar{A} k_{n}^{\beta_{n}}
$$

where $y_{n}$ is non-agricultural output per worker, $k_{n}$ is capital per worker in non-agriculture, $\bar{A}$ is total factor productivity in non-agriculture, and $0<\beta_{n}<1$, and

$$
y_{a}=\left(\kappa \bar{A} k_{a}^{\beta_{a}} z^{1-\sigma_{a}-\beta_{a}}\right)^{1-\alpha} x^{\alpha}
$$

where the lower case letters refer to per worker variables as defined before.

By capital mobility $k_{a} / k_{n}=\beta_{n} / \beta_{a}(1-\theta)$. Therefore total factor productivity in the model without capital and with capital are related as follows:

$$
A_{a}=\kappa \bar{A}(1-\theta)^{\beta_{a}}\left(\frac{y_{n}}{\bar{A}}\right)^{\beta_{a} / \beta_{n}}
$$


Using this equation, it can be readily seen that if $\beta_{a}=\beta_{n}$ then

$$
A_{a}=\kappa(1-\theta)^{\beta_{a}} y_{n}
$$

Moreover, with roughly equal capital shares $A_{a}$ and $y_{n}$ are related regardless of the source of $y_{n}$ variation: capital accumulation or technology. If instead, $\beta_{a}<\beta_{n}$ then

$$
A_{a}=\kappa \bar{A}(1-\theta)^{\beta_{a}}\left(\frac{y_{n}}{\bar{A}}\right)^{\beta_{a} / \beta_{n}}
$$

As long as the variation in $y_{n}$ is not all coming from variations in capital to output ratios, then $A_{a}$ is also roughly proportional to variations in total factor productivity. This view of cross-country labor productivity differences is consistent with the work of Klenow and Rodriguez-Clare (1997), Hall and Jones (1999), Prescott (1998), and Parente and Prescott (2000).

\section{Technology Choice in Agriculture}

Our model assumes that all countries use the same technology in agriculture. Here, we argue that introducing technology choice in agriculture would only strengthen the impact of TFP and barriers to using intermediate inputs on aggregate productivity.

Suppose we modify our model by allowing for two different technologies available in agricultural production:

$$
\begin{aligned}
Y_{a, T} & =B Z_{T}^{1-\sigma} L_{a, T}^{\sigma} \\
Y_{a, M} & =\left(\kappa A Z_{M}^{1-\sigma} L_{a, M}^{\sigma}\right)^{1-\alpha} X^{\alpha}
\end{aligned}
$$

where the first function is a traditional technology that does not use intermediate input. In this case, we can show that there exists $\Phi_{l}$ and $\Phi_{h}, 0<\Phi_{l}<\Phi_{h}$, such that that only the

traditional technology is used in agriculture if $\left(\frac{1-\theta}{\pi}\right)^{\alpha} A<\Phi_{l}$, only the modern technology is 
used if $\left(\frac{1-\theta}{\pi}\right)^{\alpha} A>\Phi_{h}$, and both technologies are used if $\Phi_{l} \leq\left(\frac{1-\theta}{\pi}\right)^{\alpha} A \leq \Phi_{h} \cdot{ }^{22}$ So, a country with low TFP or high barriers is less likely to choose the modern technology in agricultural production, causing the country to fall even further behind from rich countries in agricultural labor productivity. Because we assume that the traditional agricultural technology is less intensive in intermediate inputs, the same argument applies for the relationship between TFP and intermediate input use, that is, since low TFP reduces the use of modern technology in agriculture, less intermediate inputs are demanded by farmers.

\section{E Summary Data}

Table 6: Labor Productivity and Labor Shares across Countries

\begin{tabular}{lrrrr}
\hline \hline & $G D P / N$ & $G D P_{n} / L_{n}$ & $G D P_{a} / L_{a}$ & $L_{a} / N$ \\
\hline Rich 5\% & 30,497 & 31,582 & 12,237 & 0.05 \\
Poor 5\% & 941 & 8,262 & 173 & 0.90 \\
Ratio & 32 & 4 & 71 & $1 / 18$ \\
\hline Top 5\% & 30,497 & 33,711 & 19,249 & 0.04 \\
Bottom 5\% & 941 & 4,328 & 138 & 0.91 \\
Ratio & 32 & 8 & 139 & $1 / 25$ \\
\hline Mean & 10,904 & 15,548 & 3,057 & 0.43 \\
std(log) & 1.08 & 0.58 & 1.43 & 0.97 \\
\hline \hline
\end{tabular}

$L_{i} / N=$ labor share in sector $i, a$ denotes agriculture and $n$ nonagriculture, Top and Bottom $5 \%$ refer to the top and bottom $5 \%$ of the countries in each variable ( 5 countries in our sample), while Rich and Poor $5 \%$ refer to the richest and poorest $5 \%$ of the countries in terms of GDP per worker for all variables.

\footnotetext{
${ }^{22} \mathrm{~A}$ detailed proof of this claim is available from the authors upon request.
} 


\section{References}

[1] Adamopoulos, T., "Distribution Margins and Prosperity," manuscript, University of Toronto, 2003.

[2] Atkeson, A. and Ogaki, M. "Wealth-varying Intertemporal elasticities of substitution: Evidence from Panel and Aggregate Data," Journal of Monetary Economics 38, 1996, 507-34.

[3] Atkeson, A. and Ogaki, M. "Rate of Time Preference, Intertemporal Elasticity of Substitution and the Level of Wealth," Review of Economics and Statistics, 1997, 79, 564-72.

[4] Chari, V., Kehoe, P. and McGrattan, E. "The Poverty of Nations: A Quantitative Exploration," NBER Working Paper No. 5414, 1996.

[5] ____-_. "Accounting for the Great Depression," American Economic Review 92, May 2002a, 22-27.

[6] ___-_._. "Business Cycle Accounting," Federal Reserve Bank of Minneapolis Working Paper No. 625, 2002b.

[7] Caselli, Francesco and Coleman, Wilbur John, II. "The US Structural Transformation and Regional Convergence: A Reinterpretation." Journal of Political Economy, June 2001, 109, pp.584-616.

[8] _-_-_-_. "World Technology Frontier," manuscript, Harvard University, 2003.

[9] Echevarria, Cristina. "Changes in Sectoral Composition Associated with Economic Growth." International Economic Review, 1997, 38(2), pp. 431-52.

[10] Eswaran, Mukesh and Kotwal, Ashok. "The Role of the Service Sector in the Process of Industrialization," manuscript, University of British Columbia, 2001.

[11] Gollin, D., "Getting Income Shares Right," Journal of Political Economy 110 (April 2002), 458-474. 
[12] Gollin, D., S. Parente, and R. Rogerson, "The Role of Agriculture in Development," American Economic Review (May 2002).

[13] Gollin, Parente, and Rogerson. "Structural Transformation and Cross-Country Income Differences," manuscript, 2001, Arizona State University.

[14] Gollin, D., S. Parente, and R. Rogerson, "Farm Work, Home Work, and International Productivity Differences," Manuscript, University of Pennsylvania, 2000.

[15] Goodfriend, Marvin and McDermott, John. "Early Development." American Economic Review, 1995, 85(1), pp. 116-133.

[16] Hall, R. and C. Jones, "Why Do Some Countries Produce so much Output per Worker than Others,? Quarterly Journal of Economics (1999), 83-116.

[17] Hansen, G. and E. C. Prescott, "Malthus to Solow," American Economic Review (September 2002), 1205-1217.

[18] Hayami, Y. and V. Ruttan, "Agricultural Productivity Differences among Countries," American Economic Review 60 (1970), 895-911.

[19] Hayami, Y. and V. Ruttan, Agricultural Development: An International Perspective, Revised and Extended Edition, (Baltimore: Johns Hopkins University Press, 1985).

[20] Hsieh, Chang-Tai and Klenow, Peter, "Relative Prices and Relative Prosperity," manuscript, Princeton University, 2002.

[21] Huffman, Wallace and Evenson, Robert. Science for Agriculture: A Long-Term Perspective, (Ames, Iowa: Iowa State University, 1993).

[22] Johnson, D. Gale. "Agriculture and the Wealth of Nations." American Economic Review 87(2), May 1997, 1-12.

[23] Jones, C. I., "Economic Growth and the Relative Price of Capital," Journal of Monetary Economics 34, 1994, 359-382. 
[24] Klenow, Peter and Andres Rodriguez-Clare, "The Neoclassical Revival in Growth Economics: Has It Gone Too Far?" in Ben S. Bernanke and Julio J. Rotemberg, eds. NBER Macroeconomics Annual 1997. Cambridge, MA: MIT Press.

[25] Kongsamut, Piyabha; Rebelo, Sergio and Xie, Danyang, "Beyond Balanced Growth," Review of Economic Studies, October 2001, 68(4), pp.869-82.

[26] Krueger, Anne, Maurice Schiff, and Alberto Valdes, Eds. The Political Economy of Agricultural Pricing Policy, Vols. 1-5, (Baltimore, Maryland: The Johns Hopkins University Press, 1991).

[27] Laitner, John. "Structural Change and Economic Growth," Review of Economic Studies, 2000.

[28] Love, David. "A Dynamic General Equilibrium Model of Industrialization when Manufactures are Unnecessary." Journal of Development Economics 54, 1997, 357-85.

[29] Lucas, R.E. Jr. "Some Macroeconomics for the 21st Century," Journal of Economic Perspectives 14(1), 2000, 159-68.

[30] Lucas, R. E. Jr., "The Industrial Revolution: Past and Future," manuscript, University of Chicago, 1998.

[31] Mankiw, G., D. Romer, and D. Weil, "A Contribution to the Empirics of Economic Growth," Quarterly Journal of Economics 107 (1992), 407-38.

[32] Manuelli, Rodolfo and Seshadri, Ananth, "Frictionless Technology Diffusion: The Case of Tractors," NBER Working Paper No.9604, 2003.

[33] Matsuyama, Kiminori, "Agriculture Productivity, Comparative Advantage, and Economic Growth," Journal of Economic Theory, 1992, 58(2), pp.317-34.

[34] McGrattan, E. and Schmitz, J. "Explaining Cross-Country Income Differences," in Handbook of Macroeconomics. Volume 1A. Amsterdam, New York and Oxford: Elsevier Science, North-Holland, 669-737, 1999. 
[35] Mulligan, Casey B. "A Dual Method of Empirically Evaluating Dynamic Competitive Equilibrium Models with Market Distortions, Applied to the Great Depression and World War II," NBER Working Paper No. 8775, 2002a.

[36] __-_._. . Century of Labor-Leisure Distortions," NBER Working Paper No. 8774, $2002 b$.

[37] Mundlak, Yair. "Production and Supply," in B. Gardner and G. Rausser, eds., Handbook of Agricultural Economics, Volume 1A, Chapter 1, (New York: North-Holland Elsevier, 2001), 3-85.

[38] Mundlak, Yair. Agriculture and Econmic Growth: Theory and Measurement, (Cambridge, Massachusetts: Harvard University Press, 2000).

[39] Ngai, L.R. "Barriers and the Transition to Modern Growth," manuscript, University of Pennsylvania, 2000.

[40] Parente, S. and E. C. Prescott, Barriers to Riches, (Massachusetts: MIT Press, 2000).

[41] Prasada Rao, D.S. 1993. "Intercountry Comparisons of Agricultural Output and Productivity." FAO Economic and Social Development Paper 112. Food and Agriculture Organization of the United Nations.

[42] Prescott, E. C., "Needed: A Theory of Total Factor Productivity," International Economic Review 39 (1998), 525-549.

[43] Restuccia, D. and C. Urrutia, "Relative Prices and Investment Rates," Journal of Monetary Economics 47 (February 2001), 93-121.

[44] Rosenzweig, Mark, "Labor Markets in Low-Income Countries," in Hollis Chenery and T. N. Srinivasan, eds., Handbook of Development Economics, Vol.1, Part II, Chapter 15, 713-762. (New York: North-Holland, 1988.) 
[45] Rosenzweig, M. and K.I. Wolpin, "Credit Market Constraints, Consumption Smoothing, and the Accumulation of Durable Production Assets in Low-Income Countries: Investments in Bullocks in India," Journal of Political Economy 101, 1993, 223-244.

[46] Schultz, T.W. The Economic Organization of Agriculture, (New York: McGraw-Hill, 1953.)

[47] _-_-_ Transforming Traditional Agriculture, (New Haven: Yale University Press, 1964.)

[48] Stokey, N. "A Quantitative Model of the British Industrial Revolution: 1780-1850." Carnegie-Rochester Series on Public Policy, 55 (2001), pp.55-109.

[49] Summers, Robert and Alan Heston. 1991. "The Penn World Table: An Expanded Set of International Comparisons, 1950-1988." Quarterly Journal of Economics: 327-68.

[50] Timmer, Peter C. "The Agricultural Transformation," in Hollis Chenery and T. N. Srinivasan, eds., Handbook of Development Economics, Vol.1, Part II, Chapter 8, 276331. (New York: North-Holland, 1988.)

[51] Yang, Dennis Tao and Zhu, Xiaodong "Structural Change and the Dynamics of Industrial Revolution," manuscript, University of Toronto, 2001. 
Figure 1: Labor Productivity across Countries
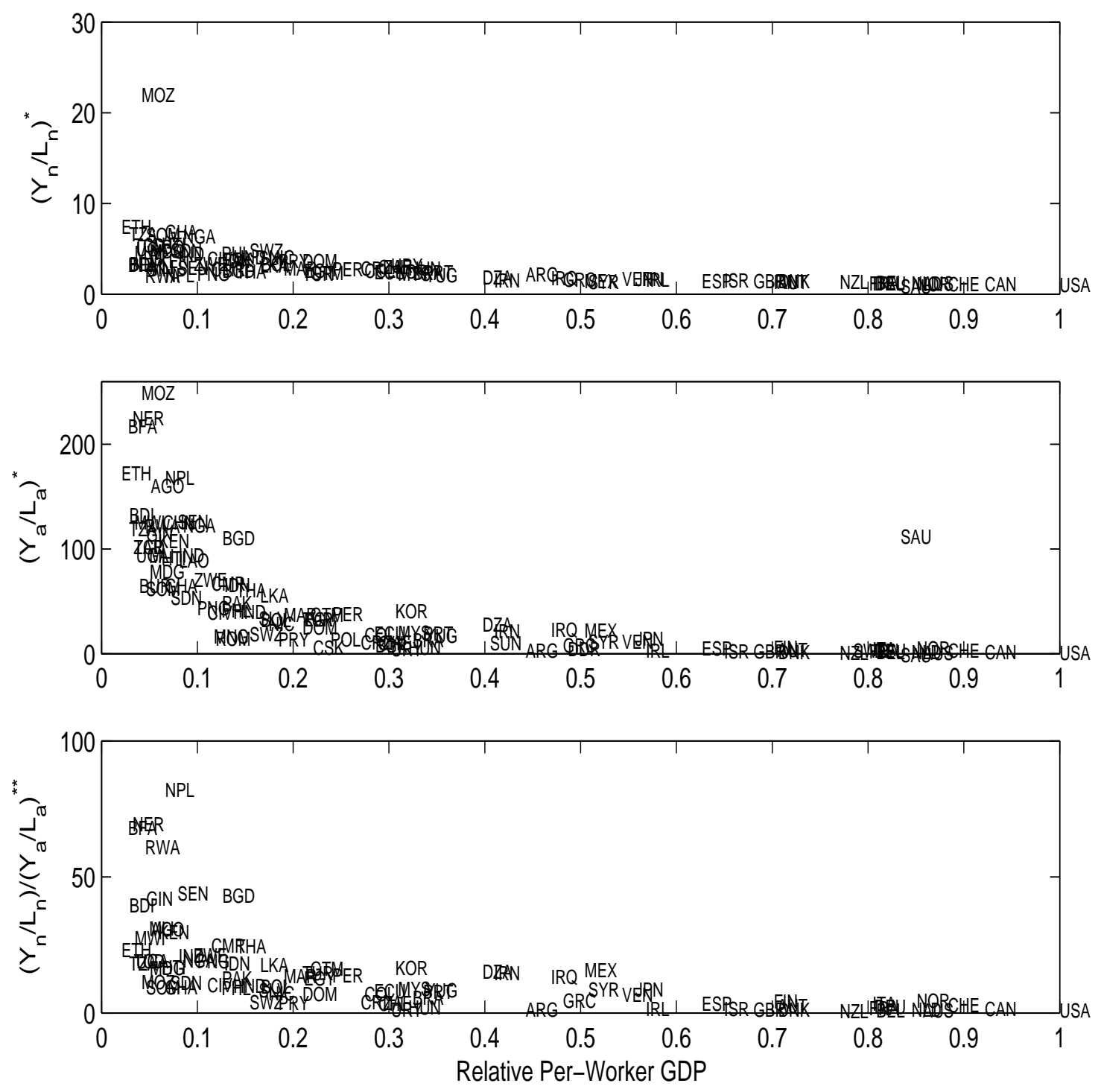

$Y_{j} / L_{j}$ is labor productivity in sector $j \in\{a, n\}$ where $a$ denotes agriculture and $n$ nonagriculture. * refers to labor productivity of the U.S. relative to country $i$. ${ }^{* *}$ refers to relative sectoral productivity in country $i$ relative to the U.S. 
Figure 2: Intermediate Input and Labor Productivity in Agriculture

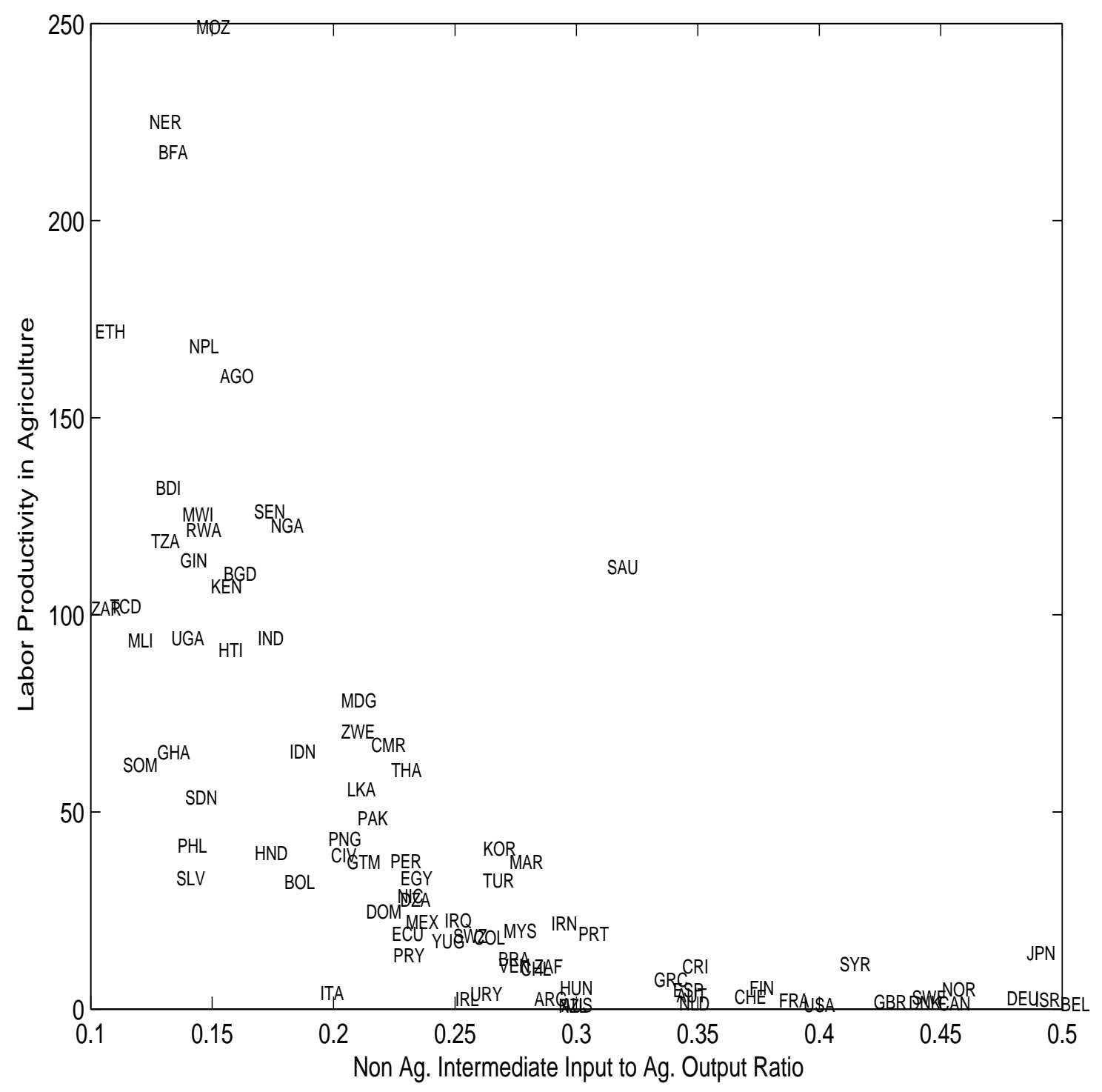

Labor productivity in agriculture is expressed as the U.S. relative to country $i$. 
Figure 3: Direct Barriers to Nonagricultural Intermediate Input Use $\pi^{*}$

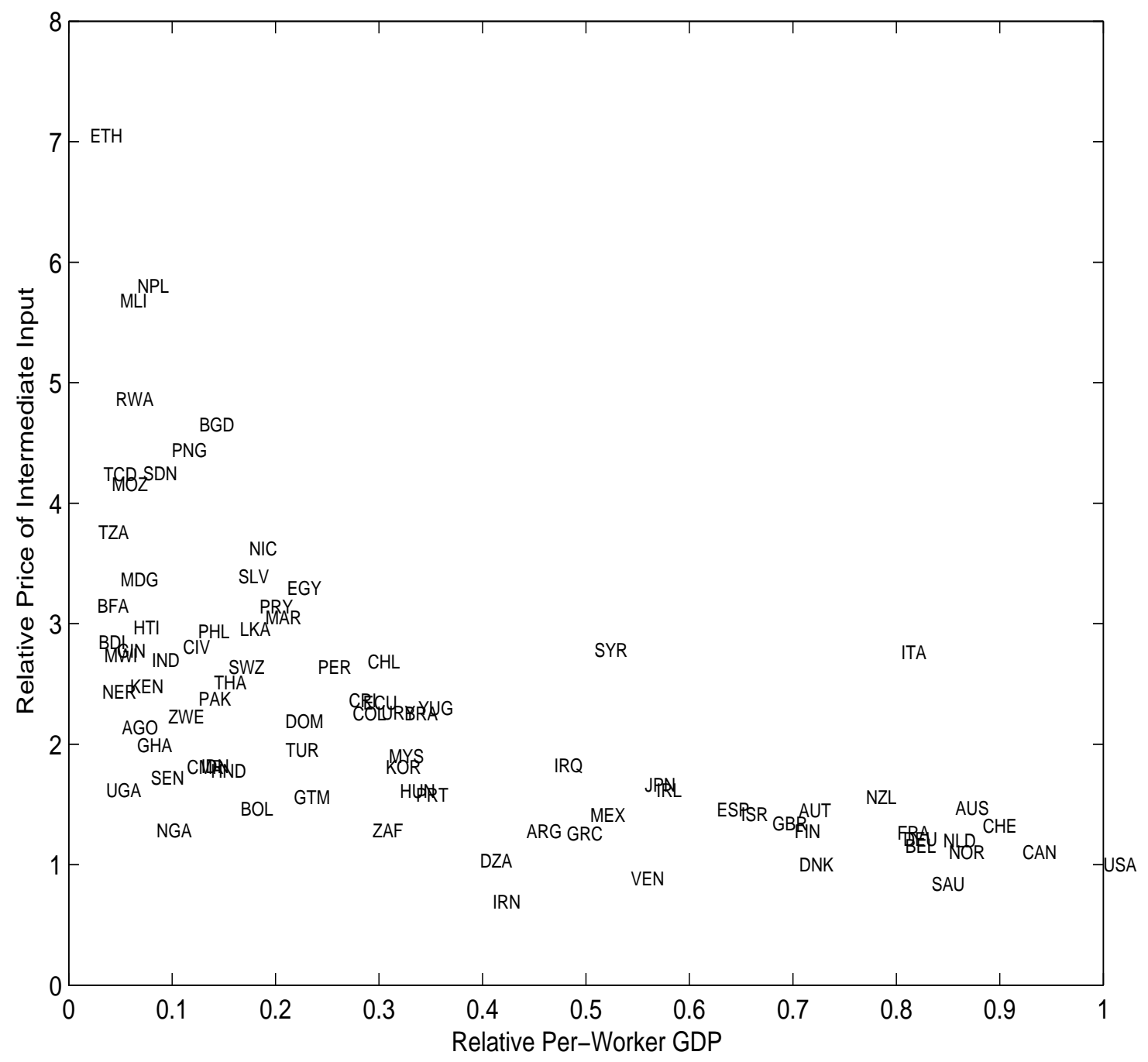

*Price of nonagricultural intermediate input relative to the price of nonagricultural output. Relative to the U.S. ratio. 
Figure 4: Indirect Barriers to Nonagricultural Intermediate Input Use $\theta^{*}$

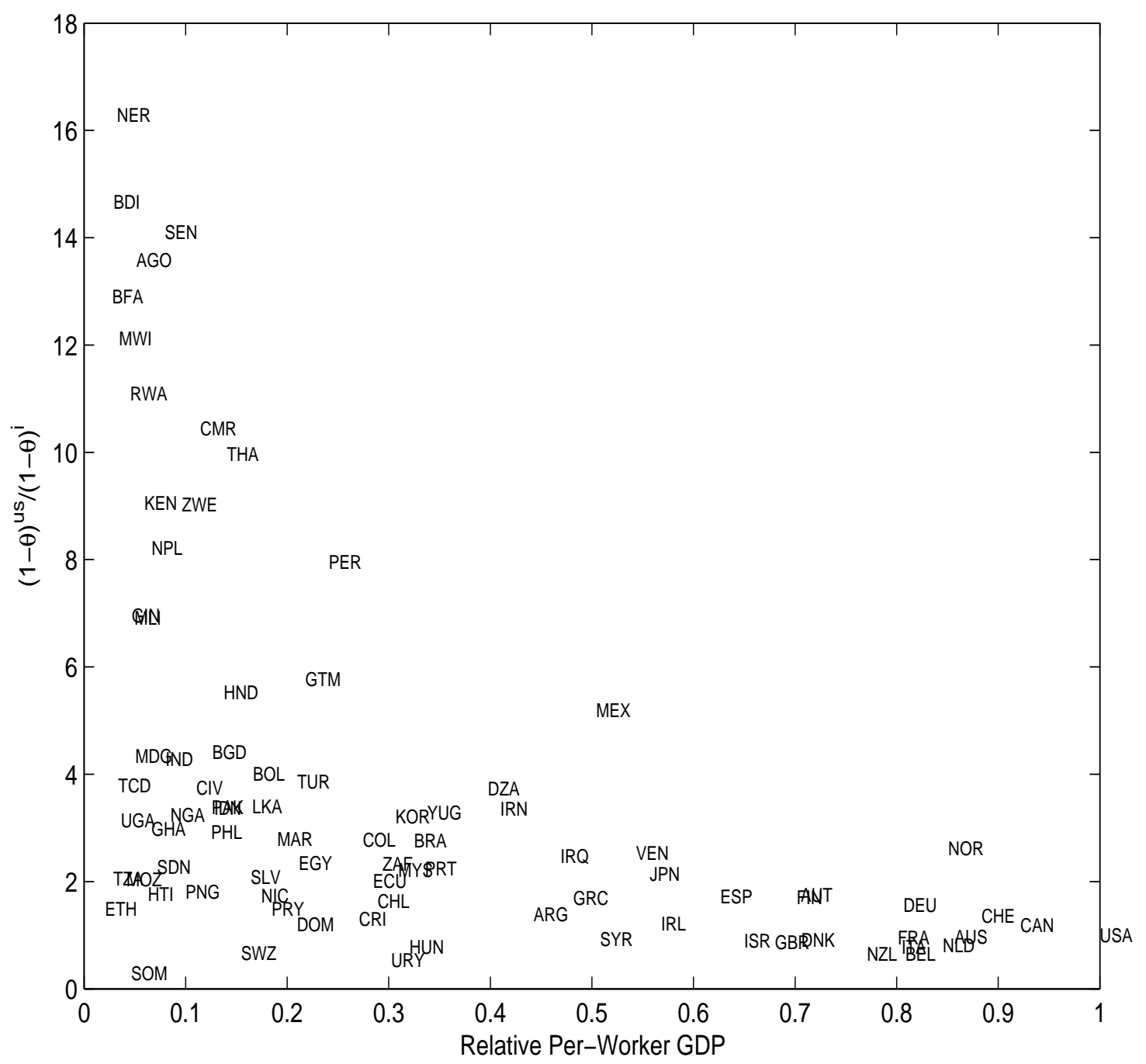

${ }^{*}$ Wage gap between the agricultural and nonagricultural sectors. U.S. gap relative to country $i$. 
Figure 5: Quantitative Results - Model vs. Data
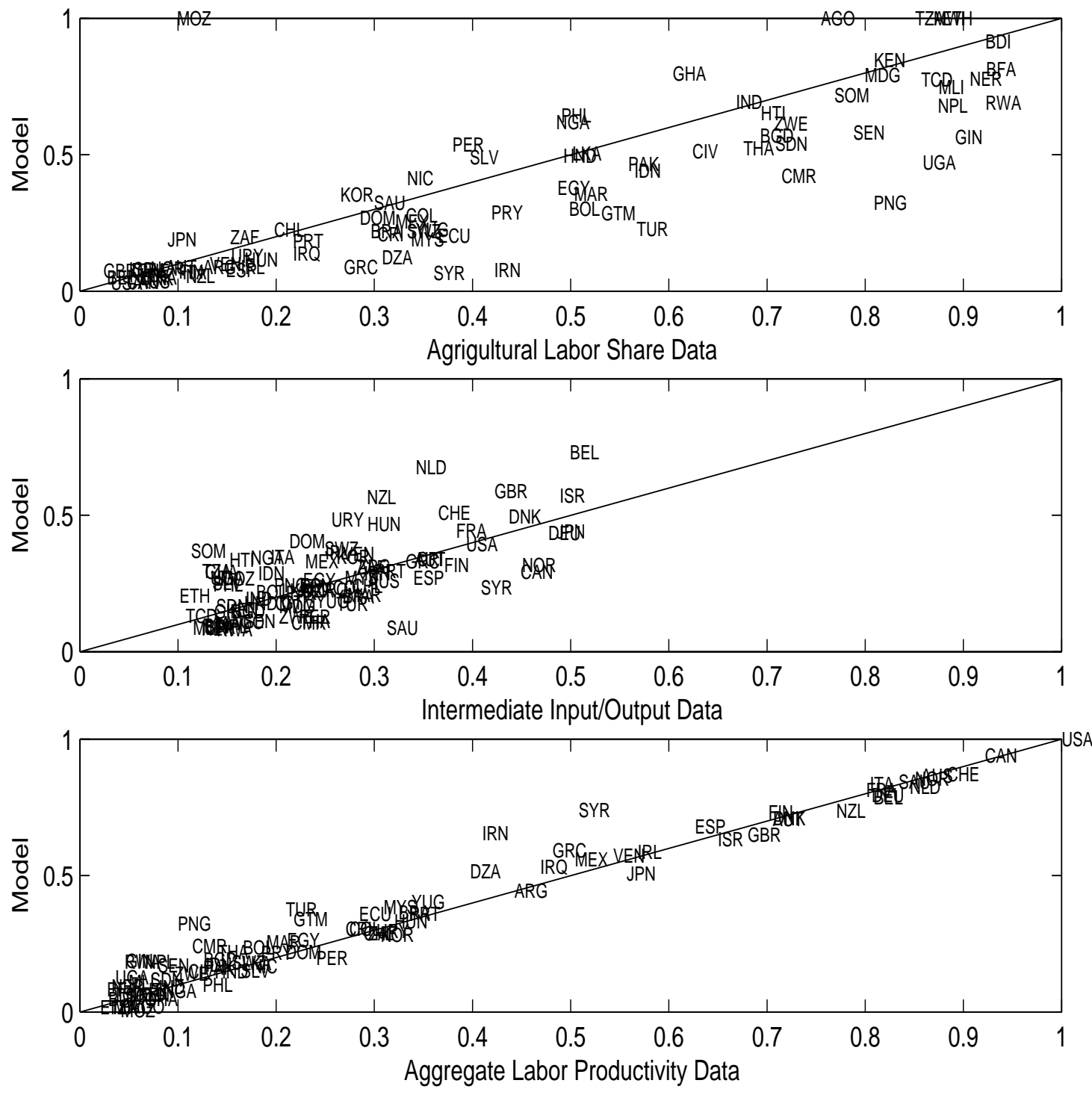
Figure 6: Agricultural and Food Prices (relative to U.S.)
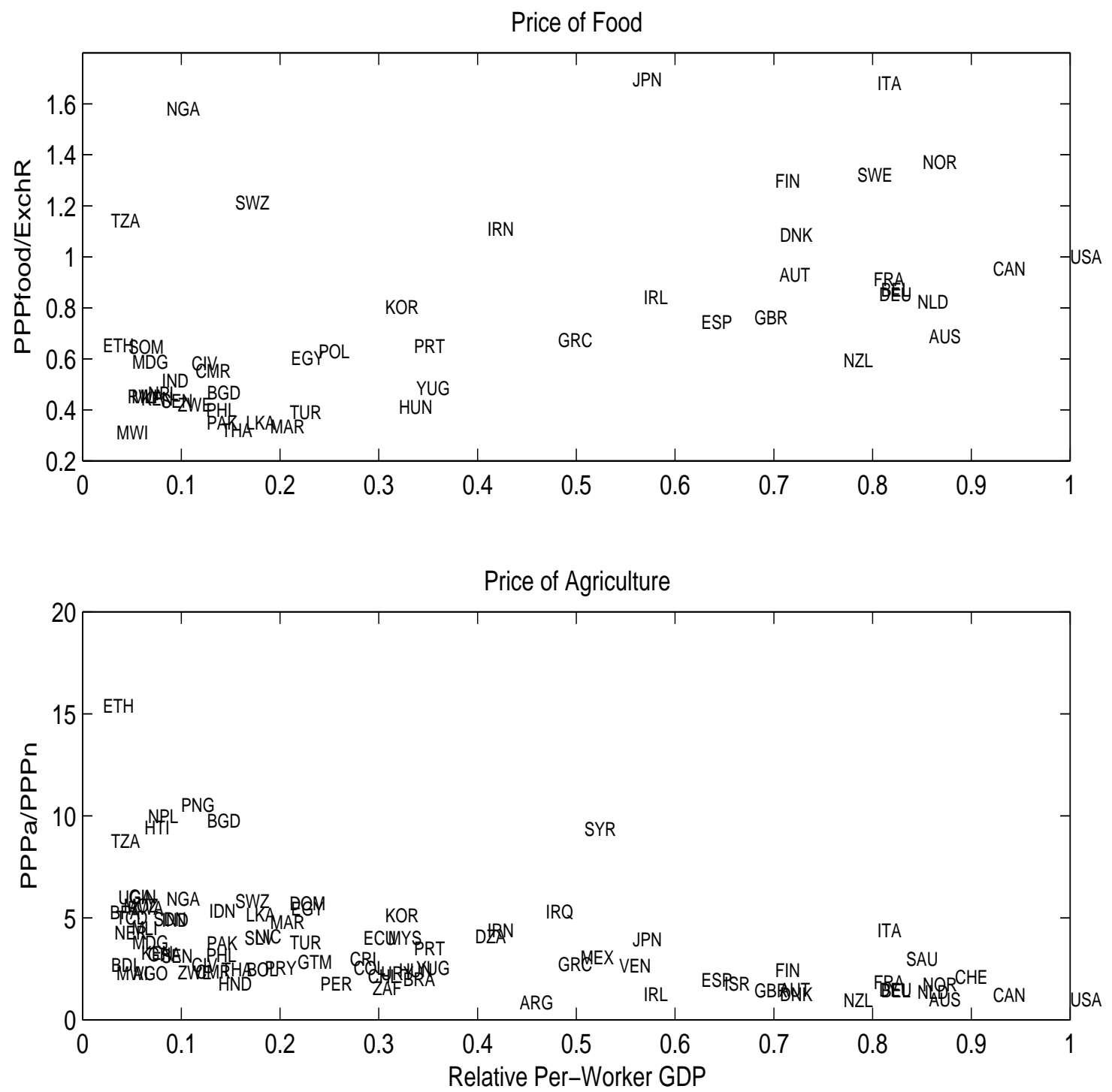

$\mathrm{PPP}_{i}$ refers to the purchase power parity of $i$ where $i=$ food, agriculture, and nonagriculture. ExchR denotes the official exchange rate. 